\title{
¿ARABISMOS O ROMANISMOS?
}

EsP. anocheci en el bosque, rum. am înnoptat în pădure

1.1. A raíz del artículo de A. Lombard, "Die Bedeutungsentwicklung zweier ibero-romanischer Verba”, $Z R P h, 5^{6}$ (1936), 637643 , los romanistas e hispanistas suelen estar de acuerdo en considerar "arabismos semánticos", o sea calcos del árabe, ciertos usos de los verbos españoles amanecer, anochecer y de los correspondientes verbos portugueses amanhecer, anoitecer. Se trata del hecho bien conocido de que esos verbos significan no sólo 'empezar a aparecer la luz del día' y 'empezar a faltar la luz del día, venir la noche' (al. tagen, Tag werden y Nacht werden), sino también 'llegar o estar en un paraje, situación o condición determinados al amanecer (o al anochecer)'; o sea, para decirlo con las mismas palabras de Lombard (art. cit., p. 637): “"den Anbruch des Tages bzw. den Einbruch der Nacht erleben», insbesondere mit Bezug auf den Ort, wo, oder auf den Zustand, in welchem dieses Erleben stattfindet, also «sich mit Anbruch des Tages bzw. mit Einbruch der Nacht irgendwo oder irgendwie befinden"”. Así, por ejemplo: amaneci en Madrid y anocheci en Toledo, amaneci con plata y anocheci sin blanca, amaneci sano y anocheci enfermo, y port. amanheci sobre os livros, amanheci doente, anoiteci em Coimbra. Tales giros "personales" se consideran como típicamente hispánicos dentro del ámbito romance y, más particularmente, como españoles y portugueses, y suelen explicarse como calcos de los usos análogos de los verbos árabes aṣbaha y amsā [o, más bien, alāla, de layl 'noche']. En efecto, estos verbos árabes significan no sólo 'faire jour, être matin' y 'faire soir [nuit]', sino también 'être au matin, devenir tel ou tel le matin' y 'être au soir, se trouver au soir [à la nuit]', exactamente como amanecer y anochecer.

1.2. Más recientemente, Américo Castro, España en su historia, Buenos Aires, 1948, p. 218 , adopta y amplía la tesis de Lombard, atribuyendo a influjo árabe también un giro como el que se encuentra en el Poema del Cid, v. 1186: amaneció a mio Cid en tierras de Mon Real. Sin embargo, en la edición revisada y modificada de la misma obra, La realidad histórica de España, México, 1954, p. 23o, tal vez como consecuencia de la discusión con Leo Spitzer, NRFH, 3 (1949), 141-158, Castro limita la explicación por el árabe a los giros 
con amanecer, anochecer, amanhecer, anoitecer conjugados en forma personal, lo cual coincide con lo sostenido inicialmente por Lombard. En esta misma forma acepta la tesis del arabismo semántico Rafael LApesa, tanto en su reseña de la obra de Américo Castro, NRFH, 3, p. 3oo, como en las ediciones $2^{\text {a }}, 3^{\mathrm{a}}$ y $4^{\mathrm{a}}$ de su Historia de la lengua española (pp. 109, 108, 110, respectivamente). Y la aceptan también, aunque con cierta cautela, Serafim da Silva Neto, História da lingua portuguêsa, Rio de Janeiro, $195^{2}$ ss., p. 344, y KuRT BALdINGer, Die Herausbildung der Sprachräume auf der Pyrenäenhalbinsel, Berlin, 1958, p. 35: el primero, con un "parecem decalques"; el segundo, con un vielleicht ('quizá').

1.3. En el bando opuesto sólo parece figurar L. SPITzER, NRFH, 3 , p. 142, quien, por otra parte, no hace referencia al artículo de Lombard, y sí sólo al libro de Castro. Pero, a decir verdad, Spitzer trata sólo del giro le amaneció a alguien, con respecto al cual aduce construcciones paralelas del francés antiguo, como il leur anuita, il lor fut avespré, de manera que sus dudas no llegan a afectar el eventual arabismo de amaneci en Madrid, amaneci enfermo (véase la respuesta de CAstro, ibid., pp. $\left.1^{1} 5^{-1} 5^{2}\right)$.

1.4. En resumen, hay tres tipos de construcciones con amanecer, anochecer, referidas de un modo $\mathrm{u}$ otro a personas: (A) le amanece a Fulano (event. el dia); (B) amanezco en Madrid ("en un paraje", "irgendwo"); (G) amanezco sano ("en una situación o condición", "irgendwie"). El estado actual del problema etimológico de estos giros es, ciertamente, el resumido por J. Corominas, DCEC, t. 3, p. 251. Corominas, de acuerdo con Spitzer, rechaza el arabismo semántico de le amaneció a Fulano en tal lugar (tipo A), pero afirma que "hay arabismo indudable en la construcción con sujeto personal Fulano amaneció" (tipos B, C).

2. En general, los varios autores que se han referido al problema después de Lombard, o no hacen mención de las demás lenguas romances, o afirman decididamente que en ellas se desconocen tales giros. Así, A. Castro, España en su historia, p. 218 , a propósito del giro amaneció a mio Cid, afirma: "Ni en latín ni en otras lenguas románicas es posible tal construcción. Más extraño aún es que amanecer se conjugue personalmente. ". En La realidad histórica..., p. 230, introduce dos limitaciones, pues se refier sólo a los tipos B y C y habla del latín y de las "lenguas literarias de Occidente", "en ninguna [de las cuales] aparece amanecer conjugado personalmente"; pero en la misma página suprime la segunda limitación: "Lo que sin duda alguna separa al español de cualquiera otra lengua románica es el uso de amanecer en primera persona". También Baldinger, op. cit., pp. 35-36, afirma que sólo en ibero-romance (esp. y port.) se da "ein persönlicher Gebrauch" de amanecer, anochecer, al lado del empleo "impersonal" documentado en francés antiguo y en 
latín ${ }^{1}$. Y Corominas, loc. cit., se expresa de manera aún más resuelta: "ésta es construcción exclusiva del castellano y el portugués dentro del romance, sin analogías en el sistema sintáctico romance”.

Es, pues, fundamentalmente la afirmada ausencia de la construcción en las demás lenguas románicas lo que orienta a los estudiosos hacia el árabe.

3.1. Ahora bien, que el tipo A no es desconocido en el romance extrapeninsular, es un hecho aceptado. Existía en francés antiguo: cum pesmes jurz nus est hoi ajurnez (Chanson de Roland); y - lo que no ha sido observado y es bueno observar- existía también en latín: omnem crede diem tibi diluxisse supremum (Horacio). Pero ¿̨será enteramente exacto decir, sin otra precisión, que "en las demás lenguas románicas faltan" los tipos $\mathrm{B}$ y C?

3.2. Hay que observar, en primer término, que por lo que toca a ciertas lenguas románicas, no es que ignoren sólo tales giros, sino que no poseen siquiera verbos correspondientes a amanecer, anochecer "no-personales", de manera que no se ve cómo podrían tener construcciones especiales con verbos inexistentes, ni qué validez puede tener el argumento de la falta de dichos giros en ellas. Así, el francés moderno no conoce tales verbos y dice il se fait jour, le jour se lève, il se fait nuit, la nuit tombe, etc. (pero cf. 3.4 y 5.5.2). En catalán, a pesar de que algunos diccionarios dan un verbo amanèixer (registrado también por el $R E W$ ), y de que el de P. Labernia (cit. por Lombard, art. cit., p. $63_{3} 8$ ) le atribuye incluso el valor de 'arribar á algun lloch al apuntar lo dia', no sólo no es corriente tal uso, sino que el verbo mismo es de documentación dudosa; Corominas, loe. cit., niega sin más su existencia: "No puede considerarse como existente un cat. amanèixer, sólo empleado por algún valenciano castellanizante" 2 . Tampoco existe en catalán un verbo correspondiente a anochecer. Y lo mismo cabe decir de otros romances, como el sardo y el friulano (cf. infra, nota 8). En italiano, finalmente, existen aggiornare y annottare, pero son verbos literarios y poco comunes (en particular el primero): las expresiones usuales no son aggiorna, annotta, sino si fa giorno, si fa notte.

3.3. ¿Cuáles son, pues, las lenguas romances de las que se pueda decir propiamente que "no conocen el uso ibérico"? Se han aducido el francés y el provenzal antiguos. Estas lenguas poseían, en efecto, varios verbos análogos a amanecer, anochecer, de frecuente uso

a Por empleo "personal" se entiende, evidentemente, un empleo con sujeto persona, ser humano, pues el mero empleo con sujeto (del tipo amanece el dia) está ampliamente documentado en francés antiguo y también en latín. Por la misma razón, en lugar de hablar de empleo "impersonal" sería mejor decir, en el mismo sentido, "no-personal".

2 Me consta, sin embargo, que el verbo (inclusive con su uso "personal") es bastante corriente en valenciano, aunque, sin duda, lo será como castellanismo. 
"no-personal”, y también (en el caso del francés) con varios empleos "personales", entre los cuales, sin embargo, no parecen estar documentados giros idénticos a los españoles y portugueses. Pero se trata precisamente de las dos lenguas en las que la inexistencia de un uso cualquiera no es un hecho verificable, puesto que "inexistencia" no es, por cierto, lo mismo que "falta de documentación" (además, con respecto al fr. ant., cf. 5.5.2).

En cambio, entre las lenguas románicas actuales, fuera del español y del portugués, hay otra que posee esos verbos como populares y absolutamente corrientes: el rumano. Pero el rumano -y es ésta la segunda observación que cabe hacer a las afirmaciones antes citadas- conoce también su uso "personal" (precisamente, el tipo B).

3.4. Por lo tanto, la situación lingüística sincrónicamente observable, y de la que conviene partir, es la siguiente: una serie de lenguas románicas, pertenecientes a dos áreas no contiguas (español, portugués, rumano), poseen como populares y usuales verbos del tipo amanecer, anochecer, y conocen asimismo un peculiar uso "personal" de esos verbos. Y todavía hay que agregar que el provenzal moderno conoce un anucha impersonal y un s'anucha personal, y que el mismo francés moderno posee un verbo s'anuiter 'anochecer', de uso exclusivamente personal (cf. 5.5.2). Esto, según todas las normas de la lingüística comparada, nos orienta de inmediato hacia un origen latino del fenómeno en cuestión.

4.1. Lo curioso es que el primero que sostuvo la tesis arábiga, A. Lombard, excelente conocedor del rumano como es, no ignoraba la mencionada coincidencia rumano-ibérica. Al contrario, afirmaba textualmente: "Die aus dem Spanischen bekannte, spezielle persönliche Konstruktion ist also eine Eigentümlichkeit der ibero-romanischen Sprachen und des Rumänischen" (art. cit., p. 639). Más aún, la tarea que se proponía en buena parte de su artículo era, precisamente, la de eliminar el problema planteado por la analogía con el rumano, para explicar por separado los giros luso-españoles.

4.2. Recordemos brevemente su argumentación (ibid., pp. 698641). Lombard comienza por señalar que también en rumano hay un verbo de empleo análogo al luso-español: a însera (por ejemplo, inserară la un sat 'anochecieron en una aldea'). Los otros verbos análogos los excluye: a întuneca sería vergleichbar aber nicht gleich", y a înnopta sería todavía diferente, pues significaría sólo "Nacht werden" ('anochecer' impers.) y "übernachten" ("pasar la noche'). Reconocida, pues, la analogía entre rumano y luso-español para un solo verbo, Lombard se pregunta si los dos usos, el oriental y el occidental, deberán considerarse como históricamente relacionados, de acuerdo con la conocida norma geolingüistica de las áreas laterales; pero rechaza tal hipótesis, porque - dice-debería tratarse de un hecho 
muy antiguo, latino, del cual, sin embargo, falta justamente la documentación latina. Por lo tanto, le parece excluido que el fenómeno pueda remontarse al latín. Además, habría que separar el rumano del romance occidental, en este caso, porque, como lo ha señalado Sandfeld, construcciones análogas a la rumana con $a$ insera se encuentran también en griego moderno, albanés y búlgaro: se trataría, en rumano, de un "balcanismo", cuya aclaración pertenecería a la "filología balcánica" más bien que a la románica. Finalmente, a insera se diferenciaría, incluso por su forma, de los verbos occidentales.

Quedaría resuelta así la dificultad inicialmente planteada, pues se trataría de dos usos independientes, a pesar de su sorprendente analogía: el uso ibérico podría explicarse por el árabe; el rumano, no explicado, debería encontrar su explicación como "balcanismo".

5.1. Esta solución de Lombard, que constituye el puntal mismo de su tesis arábiga, es sin duda muy ingeniosa. Sin embargo, considero que el cuadro lingüístico delineado en 3.4 nos obliga a dudar de su exactitud y a examinar más de cerca los argumentos explícitos e implícitos en que se funda y que, como se ha visto, son en lo esencial los siguientes:

a) en rumano habría un solo verbo (a insera) comparable con los dos verbos hispánicos amanecer, anochecer (a los cuales Lombard, de acuerdo con un informante colombiano, agrega todavía oscurecer: oscureci llorando);

b) el rum. a insera sería formalmente diferente de los verbos occidentales;

c) el uso "personal" rumano, por encontrarse también en griego moderno, albanés y búlgaro, no sería latino sino balcánico;

d) el uso "personal" no estaría documentado en latín.

Ahora bien, todos estos argumentos me parecen vulnerables.

5.2. Ante todo, el uso de a innopta (fuera del hecho de que significa $\mathrm{t}$ a $\mathrm{m}$ b i é $\mathrm{n}$ 'pasar la noche en algún lugar') no es, en realidad, diferente del de a insera, sino idéntico. E1 DLRM (Dicţionarul limbii romîne moderne, Bucarest, 1958) da para a însera: 'a se face seară' y 'a rămîne undeva pină seara, a-l apuca pe cineva seara undeva', es decir, 'sich mit Einbruch des Abends irgendwo befinden', 'être surpris par le soir'; y para a innopta: 'a se face noapte' y 'a fi surprins de noapte', o sea 'être surpris par la nuit'. Asimismo, limitándonos al uso en cuestión, el DLRLC (Dicţionarul limbii romîne literare contemporane, t. 3, Bucarest, 1957) da para a însera: '(despre oameni) a rămîne pînă seara undeva, a întîrzia pînă seara, a-l apuca pe cineva seara' (con los ejemplos ca să nu însereze pe drum y unde înserează, acolo doarme); y para a înnopta: 'a fi surprins de noapte', con ejemplos enteramente análogos: au înnoptat pe drum, 
avem să innoptăm în pădure ('anochecieron por el camino', 'anocheceremos en el bosque').

Tampoco es diferente el caso de a intuneca. En primer término, su uso personal está bien documentado para el macedo-rumano. Al ejemplo que Lombard cita según Sandfeld: nă $d z u a ̆$ ntunicară $t u$ nă hoară 'un día anochecieron en una aldea', puedo agregar este otro, que encuentro en TH. Capidan, Aromânii. Dialectul aromân, Bucarest, 1932, p. 184: ntunicai Anadulie / ń-apirii n Vinitie 'anochecí [lit. 'oscurecí'] en Anatolia, amanecí en Venecia'. Pero tal uso, aunque no registrado en el $D L R M$ ni en el $D L R L C$, existe también en daco-rumano, según me lo confirman rumanos de varias regiones. Por otra parte, el propio Lombard cita según Sandfeld el refrán care mînecă nu intunecă; y es sintomático que Capidan, al traducir al daco-rumano su ejemplo, lo haga naturalmente con el mismo verbo: "am întunecat în Anatolia" (aunque en otro lugar, p. 531, traduce la misma expresión "am înoptat în Anatolia"): no creo que se trate de un calco ocasional del macedo-rumano (dialecto materno del autor).

En daco-rumano no existe un verbo exactamente correspondiente a amanecer (se emplean varias perífrasis: a se face ziuă, a se zori de ziuă, a se crăpa de ziuă, etc.); pero sí existe en macedo-rumano, donde tiene también empleo "personal": es el apir del ejemplo que se acaba de señalar; cf., de todos modos, CAPIDAN, p. 148: apir 'se luminează' ('amanece') y, con valor personal, 'mă apucă ora dimineţii' ('amanezco'), 'mă scol dis de dimineaţă' ('madrugo').

Finalmente, por propia experiencia, puedo agregar un quinto verbo: a amurgi 'dämmern', cuyo uso "personal", a pesar de que no figura en los dos diccionarios antes citados, me es absolutamente familiar: am amurgit in pădure 'la hora del crepúsculo me sorprendió en el bosque'.

Por consiguiente, no se trata de "un solo verbo" análogo a amanecer, anochecer. En rumano existen c in c o verbos análogos a los dos ibéricos: a insera, a înnopta, a intuneca, a amurgi y mac.-rum. apir, y los cinco, sin excepción, se emplean también personalmente, en el sentido de 'hallarse en algún paraje', etc.

5.3. En cuanto a la forma de a insera, no acierto a ver en qué es diferente. Si se trata de la formación en - $a$, es análoga a lat. vesperat, fr. ant. ajorner, anuitier, avesprer, prov. anucha, it. annottare. Si se trata del prefijo, es análoga a lat. illucescit, fr. enserer, enjorner (cit. por Lombard, p. 638), ennuyter (Du Bellay); por otra parte, a formaciones con $a d$ - en las lenguas occidentales corresponden en rumano, varias veces, formaciones con in-: esp. abrazar, it. abbracciare, rum. a imbrățişa; esp. ablandar, rum. a îmblinzi, etc. Por último, si se trata de la base, $a$ insera es, sin duda, diferente de anochecer, anoitecer, pero es que se trata de otro verbo. 
5.4 Tampoco alcanzo a ver en qué sentido la existencia del giro en varias lenguas balcánicas podría anular su eventual latinidad en rumano.

En primer lugar, y desde un punto de vista general, "balcánico" no significa de por sí "no-románico". Los hechos rumanos sólo podrían eliminarse si se les diera otra explicación histórica; pero decir de un hecho determinado que es "balcanismo" no. significa explicarlo, sino sólo indicar su área de difusión, comprobar que se encuentra en las lenguas de la llamada "liga lingüística" balcánica. Históricamente, en efecto, un "balcanismo" no es ningún fenómeno de naturaleza especial o que tenga alguna explicación fuera de lo común: como todo hecho lingüístico que se registra en varias lenguas contiguas $\mathrm{A}, \mathrm{B}, \mathrm{C}, \mathrm{D}-\mathrm{y}$ fuera del caso de creaciones independientes-, o se ha difundido de una de ellas a las demás, o procede en todas ellas de otra lengua E, desaparecida. En la primera hipótesis, el centro de difusión del giro podría muy bien ser el rumano, como en tantos otros casos. En la segunda, el giro podría proceder de un sustrato traco-ilirio, pero también del latín balcánico y oriental, continuado justamente por el rumano.

En segundo lugar, el mismo autor en quien Lombard se apoya, K. SANDFeld, Linguistique balkanique, Paris, 1930, pp. 210-211, no destaca siquiera el hecho como "balcanismo" específico; al contrario, lo señala en un contexto en el que observa que es justo considerar dentro de la unidad balcánica también hechos no específicos; y precisamente lo cita como un uso análogo al de esp. anochecer, fr. ant. anuitier [?] y de un fr. dial. anuiter, con el valor de 'être surpris par la nuit, se trouver dans un lieu à l'approche de la nuit'.

$5 \cdot 5 \cdot 1$. Sólo queda, pues, la circunstancia de que el uso "personal" no está documentado en latín, que es el argumento filológicamente más poderoso - pero no más poderoso que el argumento de la extensión románica del giro y de su distribución en tres zonas discontinuas (español-portugués, francés-provenzal, rumano).

Aun dejando de lado el hecho de que la norma de las áreas laterales (como las otras normas espaciales de Bartoli) se ideó para servir como indicio precisamente en los casos en que carecemos de documentación, y de que, por consiguiente, la falta de documentación no puede en rigor oponérsele, se trata aquí de una norma bien establecida de la gramática comparada románica, que recordaré en la clara formulación de M. L. WAGNER, "Über die Unterlagen der romanischen Phraseologie", VKR, 6 (1939), p. 1: "In der Wortforschung ist es längst Regel, ein in allen romanischen Sprachen oder doch in mehreren von ihnen vorkommendes Wort, auch wenn es lateinisch nicht überliefert ist, auf eine lateinische Grundform zurückzuführen. . Natürlich muss dasselbe von der Syntax gelten". A esta formulación cabría agregar sólo que no debe tratarse (como 
no se trata en nuestro caso) de hechos que podrían explicarse por difusión de una lengua a otra, después de la fase común.

El mismo Wagner subraya, con razón, lo precario e insuficiente de la documentación latina antigua por lo que atañe a la sintaxis y fraseología, y señala (p. 3) como de muy probable origen latino, a pesar de que en latín no se halla documentado, justamente un giro que hoy sólo existe en los dos extremos de la Romania: esp. no cabe duda, rum. nu încape îndoială.

5.5.2. Contra el argumento de la falta de documentación habla también la curiosa situación que se comprueba en una de las tres zonas en cuestión, la representada por el francés y el provenzal actuales.

En efecto - prescindiendo del fr. dial. anuiter aducido por Sandfeld, que no encuentro confirmado en otra parte $^{3}$-, de los varios verbos análogos a amanecer, anochecer que poseía el francés antiguo, el francés literario moderno ha conservado uno solo: s'anuiter, de forma reflexiva y de empleo exclusivamente personal. Lombard (p. 638) excluye de la discusión este verbo, diciendo que significa 's'exposer à être surpris en chemin par la nuit'. Pero, en realidad, s'anuiter no puede quedar excluido, pues significa 'se laisser surprendre par la nuit' (Larousse), 'être surpris par la nuit', 'sich bis in die Nacht verspäten' (KörTing, Lat. Rom. Wb.), 'von der Nacht überrascht werden' (GAMILlscheg, EWFS), es decir, exactamente 'anochecer', como se deduce también de los ejemplos que los diccionarios citan: il est dangereux de s'anuiter dans les montagnes 'es peligroso anochecer en las sierras'. 'Se laisser surprendre', 's'exposer à' son perífrasis que los lexicógrafos emplean para destacar el sentido "personal" del verbo, y "en chemin" es un agregado superfluo de Littré4. Por otra parte, los diccionarios rumano-franceses traducen s'anuiter, con mucho tino, por a innopta (cf., por ej., N. CondeEscu, Dictionar francez-romin, Bucarest, 1959) y, viceversa, Sandfeld traduce rum. a insera por 'être surpris par la nuit' [lit. 'par le soir'], o sea con la misma perífrasis que los diccionarios emplean para explicar s'anuiter. El uso de este verbo es, por lo tanto, enteramente análogo al de amanecer, anochecer "personales".

Ahora bien, por su forma, s'anuiter continúa, sin duda, el antiguo

3 Conozco, en verdad, un anuiter empleado en el francés regional del Sur de Francia, pero sólo en el sentido de 'pasar la noche'. Goderroy, Dict. anc. lang. $f r$., p. 304, señala tres verbos regionales, pero ninguno con el significado dado por Sandfeld: annuiter (Francia central) 'passer la nuit, dormir', enneuter (Morvan) 'mettre en nuit, dans la nuit', y aneussai (Poitou, Vendée) 'commencer à faire nuit'. Para el franco-provenzal encuentro en A. Duraffour, Lexique patois-fr. du parler de Vaux-en-Bugey (Ain), Grenobles 1941, adorna y anẅeta,

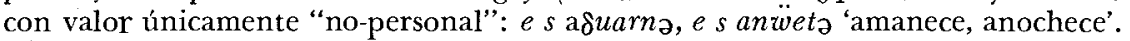

4 El mismo Littré, en efecto, explica anuité simplemente como 'surpris par la nuit'. 
(s')anuitier; pero se indica que su valor semántico es de documentación reciente, ulterior al siglo Xvi (BLoch-WARTBURG), mientras que el uso no-personal del verbo antiguo anuitier está documentado desde el siglo xI (se encuentra ya en el Alexis, v. 5 1). ¿Será una innovación moderna difícil de explicar, o se tratará, más bien, de conservación de un uso antiguo que, por un azar, no se encuentra documentado? El mismo aislamiento de ese valor en el francés actual es un indicio de lo segundo. Por otra parte, el verbo antiguo -contrariamente a lo que afirman Lombard (p. 638) y Baldinger (loe. cit.), que sólo le reconocen empleo "no-personal"- está ampliamente documentado también en varios usos "personales", si no idénti eos, por lo menos bastante cercanos al moderno. Godefroy, Lexique anc. fr., da para anuitier: 'demeurer la nuit, passer la nuit'; y para s'anuitier: 'se loger pour la nuit', 'passer une partie de la nuit à faire quelque chose'; cf. también Tobler-Lommatzsch, Altfr. $W b$. , col. 407 (donde, sin embargo, sólo se da el valor 'nächtigen'). $\mathrm{Y}$, en verdad, yo no estaría siquiera tan seguro de que el uso de s'anuitier 'anochecer' personal carece de documentación. En efecto, la traducción por anochecer conviene sin violencia ninguna a los varios ejemplos que del empleo de este verbo ofrece Godefroy: Son seigneur l'emmena et s'anuita en la ville de Gabal (Livre du Chevalier de La Tour); elle ne s'osa arrester ne anuyter sur le chemin (Froissart); Ainsi comme Nostre Seigneur s'estoit anuittié de nuit en oroison (Vita Christi). Para este último ejemplo en particular, la traducción por anochecer parecería la más adecuada: 'así como Nuestro Señor había anochecido orando'. Las traducciones de Godefroy parecen más bien acepciones contextualmente determinadas de un valor único, en todo análogo al de esp. anochecer. Es cierto que esos ejemplos son tardíos (siglos xiv-xv), pero de todos modos son anteriores al siglo XvII, e inclusive a 1500 , y por lo tanto corresponden todavía al francés medieval.

Más clara aún, en el mismo sentido, es quizá la situación que presenta el provenzal moderno (lengua no tenida en cuenta por Lombard), aunque aquí la documentación de usos personales antiguos parece faltar por completo. El provenzal moderno posee tres verbos de nuestra serie: ajourna, avespra y anucha. Los dos primeros son sólo impersonales, pero el último tiene los dos usos: es impersonal en la forma activa, y personal en la reflexiva. Mistral, Tresor, da para anucha (aniucha, aniecha, etc.): 'se faire nuit', y para s'anucha: 's'anuiter, se mettre à la nuit'; además, traduce nous anuchan por 'la nuit nous gagne', es decir, 'nos alcanza la noche, nos anochece, anochecemos', y registra interesantes ejemplos de valor personal para el participio del mismo verbo: Li plang desespera d'uno maire aniuchado; Pastourello aniechado al miech de son troupèl.

Así, pues, los hechos del francés y provenzal modernos son, en 
el fondo, muy semejantes a los que se comprueban en daco-rumano. En los tres idiomas, el uso personal existe sólo con respecto a la noche, con la diferencia de que el daco-rumano posee varios verbos con tal uso, mientras que el provenzal y el francés poseen un solo verbo personal, y de que en francés este verbo es sólo personal.

$5 \cdot 5 \cdot 3$. Pero supongamos que se quiera plantear el problema desde el punto de vista "balcánico" y, más exactamente, desde el punto de vista del griego moderno, lengua que, como es sabido, presenta pocos "balcanismos" de sustrato traco-ilirio: sus "balcanismos" más antiguos suelen ser, o grecismos que se han difundido en las demás lenguas balcánicas, o latino-romanismos. ¿A qué conclusiones llegaremos?

En griego moderno existen tres verbos análogos a esp. amanecer

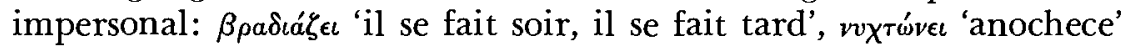

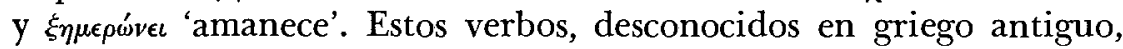
son evidentemente de formación tardía: $\xi \eta \mu \epsilon \cos _{\nu \epsilon}$ tiene documen-

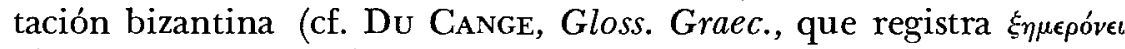


Atenas, 1951); los otros dos, sólo documentación moderna ${ }^{5}$. Más aún, el griego antiguo -lengua cuya documentación, incluso sintáctica y fraseológica, es incomparablemente superior a la latina- no poseía este tipo de verbos (es decir, verbos correspondientes a los sustantivos 'día', 'tarde', 'noche'): empleaba perífrasis, o bien imágenes

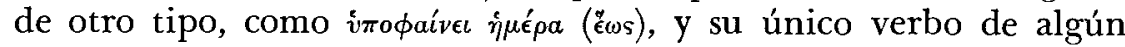
modo comparable con los que aquí consideramos, $\delta \epsilon i \lambda o \mu a \imath$ (por lo demás, de escasa documentación y de empleo limitado), no se ha conservado en el griego más reciente. En cambio, una lengua con la que el griego convivió largamente en la Península balcánica, el latín, poseía varios de estos verbos, que formaban una larga serie impersonal con otros, de otro tipo. Ya en latín clásico se registran VESPERASCIT, ADVESPERASCIT, NOGTESCIT, en serie con lucescit, luciscit, dilucescit, illucescit, tenebrescit, contenebrescit, contenebrascit; $\mathrm{y}$, más tarde, también MANESCIT, vESPERAT. Es razonable suponer que

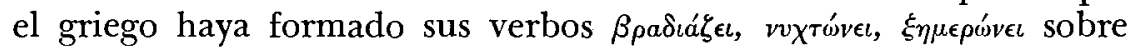
modelos latinos, para traducir verbos como vESPERASCIT, NOCTESCIT, (dilucescit): se tratará, pues, de calcos del latín. Por otra parte, en el mismo griego moderno, esos tres verbos tienen también uso per-

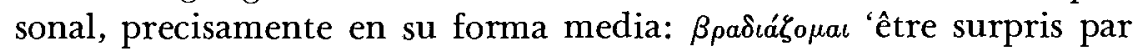

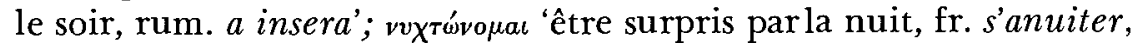

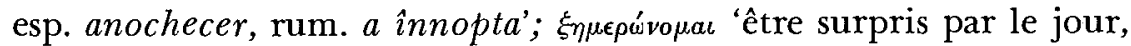
"le jour me trouve à", esp. amanecer, mac.-rum. apir'. Tal uso no puede proceder del griego antiguo, donde no existían siquiera los verbos, y tampoco se halla documentado en latín. Pero se registra

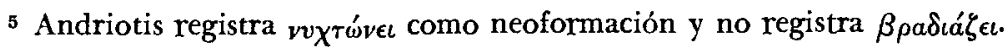

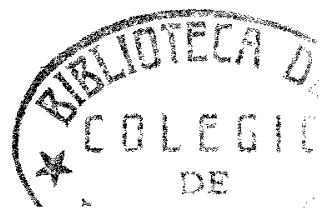


en albanés, lengua profundamente latinizada y romanizada, y se encuentra ampliamente difundido en las lenguas románicas actuales de las dos Romanias: rumano, español, portugués, francés, provenzal; en particular, es muy corriente en la lengua románica que continúa el mismo latín oriental con el que convivió el griego, es decir, en rumano. Muy razonablemente concluiremos que también este uso habrá existido en latín.

5.5.4. Por lo tanto, también el planteamiento del problema desde el ángulo balcánico y griego nos lleva hacia una solución latinorománica $^{6}$. Y será, además, razonable suponer que, en latín, el uso personal habrá surgido primero en el verbo o en los verbos de base noct-, dado que en ellos se encuentra en cinco lenguas románicas, y que luego, quizá ya en fase romance, y de manera independiente, se habrá extendido a otros verbos. En efecto, los otros verbos de la serie, o simplemente no existen, o presentan formaciones diferentes en las distintas áreas romances, o no conocen el uso personal.

Si hay arabismo en los giros personales de amanecer, anochecer, consistirá apenas en la extensión del uso del tipo B (amanecer en algún lugar) al tipo $\mathrm{C}$ (amanecer de cierto modo), pues este último, efectivamente, no se encuentra en francés y tampoco me consta que exista en rumano. Pero, aun así, habrá que tener en cuenta que el

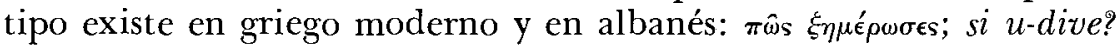
‘¿cómo has amanecido?'; u-di nestret shëruar 'al día siguiente amaneció sano' (K. SANDFELD, op. cit., p. 211 ); y habrá que tener en cuenta asimismo que el ejemplo francés medieval anuittië en oroison y el uso provenzal moderno (cf. 5.5.2) no implican referencia a un paraje. Con todo, lo más acertado será postular un normal desarrollo interno, pues es sabido que las lenguas hispánicas presentan los dos usos en varios verbos "de movimiento y estado" (como andar, salir, estar; por ejemplo, anda por ahi, anda enfermo) que en las demás lenguas romances tienen sólo sentido "espacial" o que, de todos modos, no suelen construirse con adjetivos o frases adjetivas: en el fondo, semánticamente, anochecer pers. no es otra cosa que 'estar (al caer la noche)' y, por lo tanto, puede entrar en las varias construcciones de estar.

6.1. Ciertamente, dado el carácter particular de las explicaciones históricas ${ }^{\tau}$, los giros estudiados podrían ser arabismos en ibero-romance y tener otra explicación en rumano. Pero tal solución no sólo deja inexplicado el hecho románico oriental, enteramente análogo

${ }^{6}$ Huelga decir que ello no afecta en nada la eventual significación de los giros con respecto al modo de vivir y pensar hispánico, buscada por don Américo Castro; significación que se encuentra, evidentemente, en otro plano y no en el del mero origen de las tradiciones lingüísticas.

$\checkmark$ Cf., a este propósito, E. Coseriv, Sincronia, diacronia e historia, Montevideo, 1958 , pp. 81 ss. 
al occidental, sino que, además, deja de lado el fr. s'anuiter y el prov. s'anucha, para los cuales habría que buscar una tercera explicación, pues no serán "arabismos" ni "balcanismos". Deben invocarse motivos muy poderosos para rechazar la explicación románica, que es única y abarca el francés, el provenzal, el rumano y los Balcanes.

6.2. Es cierto también que, mientras el uso personal no se encuentre documentado en latín, podrán subsistir dudas: no habrá p r u e b a filológica, sino sólo a $\mathrm{rg} \mathrm{u}$ m e n t os de orden lingüístico para sostener el origen latino de los giros. Pero argumentos que me parecen lingüísticamente suficientes. Y, de cualquier modo, si la tesis arabista se funda en que los giros personales de amanecer, anochecer no se encontrarian en otras lenguas románicas, tal argumento no es válido, pues por lo menos el tipo B se encuentra en la mayoría de las lenguas que poseen los verbos correspondientes ${ }^{8}$. Las excepciones, a lo que se me alcanza, son el franco-provenzal y el italiano; pero también el ital. annottare conoció por lo menos un uso personal, en el sentido de 'pasar la noche' (ZrNGARELLI), como el fr. ant. anuitier, el fr. regional anuiter (cf. nota 3) y el rum. a înnopta. $\mathrm{Y}$, de todos modos, se trata de dos idiomas románicos contra cinco.

\section{OTRAS EXPRESIONES: ojo de agua; casa}

7.1 La confrontación con el rumano puede hacer surgir dudas también con respecto a otros presuntos arabismos -que, por otra parte, ya han suscitado reservas. Así, por ejemplo, con respecto a ojo (de agua), port. ôlho-de-água, en el sentido de 'manantial que surge en un llano', 'nascente que rebenta no solo' (Galdas Aulete, Dicionário cont.), y a casa, en el sentido de 'habitación o cámara dentro de una casa'.

7.2.1. Por lo que se refiere a ojo de agua, ya M. L. WAGner, en su art. cit. de 1933, p. 11, señaló la coincidencia entre la expresión española y el árabe 'ayn 'ojo' y 'fuente', observando que sería posible hablar de calco; pero advertía que la misma imagen se encuentra en persa y en vascuence. En cambio, A. Castro, España en su historia, p. 63, afirma que el valor 'manantial' de esp. ojo, port. ôlho "es una acepción inexplicable dentro del románico" y la atribuye sin reservas a "seudomorfosis" (calco) del árabe; luego, a propósito del cat. ull d'un rio, habla de "mozarabismo" (pp. 79, 81); cf. también La realidad histôrica de España, pp. 112, 114. Y SPITzER, NRFH, 3, p. 141, incluye este caso entre aquellos en que Castro habría "acer-

8 Los verbos sard. arbèskere, iskurikare e ital. albeggiare, imbrunire se encuentran en una situación diferente, pues, aunque análogos a esp. oscurecer, rum. a intuneca, no pueden apoyarse, como éstos, en la analogía de un uso personal de verbos como anochecer, a innopta. Lo mismo cabe decir de los friulanos alboreá, lampená, scurí. 
tado a encontrar la base semántica árabe de ciertas palabras españolas", si bien señala en nota que G. Rohlfs, Bayerische Sitzungsberichte, $1944 / 46$, fase. 5 , ha encontrado la misma metáfora en vasco, en gascón y en Córcega, y le supone un origen vascuence [recte: ibérico].

En realidad, ya varios años antes, en Le Gascon, Halle, 1935, p. 31, RoHLFs - volviendo a una observación todavía anterior ("Baskische Relikwórter", $Z R P h, 47,1927$, p. 395)- había señalado ojo 'Quelle' en gascón (ouelh d'aigo), catalán, aragonés (güello de ra fuande) y castellano (ojos del rio Guadiana), observando que, puesto que la imagen se encuentra también en vascuence (urbegi 'fuente', prop. 'ojo del agua'), "darf man mit einiger Sicherheit vermuten, dass der Ausgangspunkt für diese metaphorische Anschauungsweise im Iberischen liegt". En la obra aludida por Spitzer, Griechischer Sprachgeist in Süditalien, München, 1947, p. 9, retomaba simplemente la misma hipótesis y se limitaba a agregar al área románica de la expresión el corso occhiu ${ }^{9}$.

En NRFH, 3, $157^{-1} 5^{8}$-esta vez con referencia explícita a Rohlfs-, CAsrro vuelve a sostener la tesis del origen árabe, argumentando que el vascuence debió tomar la imagen del romance, que también el hebreo tiene hayin 'ojo' y 'fuente', y que Córcega estuvo en poder de los sarracenos desde mediados del siglo Ix hasta mediados del xi. El origen árabe fue aceptado luego por LAPEsA (en su ya citada reseña, $N R F H$, 3, p. $\left.29^{8}\right)^{\mathbf{1 0}}$ y, como mera posibilidad, por Silva Nero, Hist. da lingua port., p. 344, quien observa que se trata de una comparación elemental y evidente y recuerda que ya Gabelentz la registraba en varias lenguas.

Finalmente, Corominas, $D C E C$, s. v. ojo, recapitula todo el asunto $\mathrm{y}$, en primer lugar, amplía la documentación de la imagen. Al área románica ya conocida (cast., arag., port., cat., esp. de América, gascón, corso) agrega el prov. uiau 'petit gouffre qu'on regarde sans fond' (Mistral), y observa que "no se puede asegurar que no tenga mayor extensión”. Al área no románica (vasco, árabe, hebreo, persa) agrega el galés, el servio-croata, el georgiano y lenguas americanas como el araucano y el quechua. En cuanto al origen, Corominas, que ya en $1937, V R, 2$, p. 158 , había pensado en la posibilidad de la poligénesis, asegura ahora, frente a la extensión de la metáfora, que se trata precisamente de un fenómeno poligenético, lo cual eliminaría las dos hipótesis antes señaladas (la arábiga y la ibérica).

7.2.2. En verdad, la poligénesis de la metáfora parece indudable y sólo cabe confirmarla, pues, en efecto, su área de extensión es

9 Por otra parte, Rohlfs (en ambas obras) no dejaba de señalar que la misma imagen se encuentra también en árabe.

10 Sin embargo, LApesa no incluye ojo de agua entre los "arabismos semánticos" en ninguna de las ediciones de su Historia de la lengua española. 
mucho mayor aún que la indicada por Corominas. Al área románica occidental debe añadirse el siciliano (el pequeño Dizionario siciliano-italiano de V. Nicotra, $2^{a}$ ed., Catania, s. f., único que puedo consultar en este momento, registra occhiu d'acqua 'polla', es decir, 'manantial'); al área no-románica, el turco göz 'ojo' y 'fuente', y -de acuerdo con G. von der Gabelentz, Die Sprachwissenschaft, $2^{\mathrm{a}}$ ed., Leipzig, ı 19o1, p. 42- el siamés, el tibetano, el malayo, el japonés, lenguas de África y de Oceanía (islas Fidji) ${ }^{11}$. En la poligénesis han pensado, como se ha visto, también Wagner y Silva Neto, y, por otra parte, ésta misma era, ya en 1901, la idea de Gabelentz, quien citaba la metáfora justamente como ejemplo de creación poligenética: "Weit verbreitet ist es, die Quelle ais Auge des Wassers zu beschreiben... Der Vergleich muss doch dem naiven Geist recht nahe liegen" (loc. cit.).

7.2.3. Sin duda. Pero ¿qué significa "poligénesis”? El concepto y su valor para la etimología necesitan ciertos esclarecimientos que merecen una pequeña digresión, pues a este respecto, sobre todo cuando se trata de imágenes "evidentes", se da todavía una frecuente y curiosa identificación entre la vieja etimología, entendida como búsqueda del "étymon", y la etimología como estudio histórico de tradiciones léxicas.

En efecto, "poligénesis" significa sólo "creación análoga en varias zonas independientes", y ello no supone de ningún modo que en todas y cada una de las lenguas en que se encuentra una imagen, haya surgido ésta independientemente: no excluye los préstamos o calcos mutuos en una área determinada. No sólo en la lingüística, sino en general en la historia de la cultura, el recurrir a la poligénesis con respecto a un hecho cultural (una "tradición”) cualquiera significa sólo afirmar la pluralidad (independencia) de las áreas en que se da tal hecho (lo cual nos permite dejar de considerar ciertas áreas), pero no resuelve el problema histórico para una área en particular. Así, afirmar la poligénesis del teatro puede significar que los hombres en general son capaces de crearlo y que el teatro europeo es independiente del chino, pero no nos exime de buscar los orígenes históricos del teatro occidental, y no significa ni que el teatro de los varios países occidentales haya surgido independientemente en cada uno de ellos ni que no continúe, en esta área, la tradición helénica. Del mismo modo, en linguística, afirmar, por ejemplo, la poligénesis del artículo significa reconocer que se da en varias lenguas no relacionadas entre sí, pero no significa renunciar a explicar históricamente el artículo románico y excluir de antemano su muy probable relación con el artículo griego. En otras palabras, "poligénesis" no significa "no-historia", sino "poli-historia": varias historias autónomas.

11 Una imagen algo diferente es la representada por el checo morské oko, eslovaco morské oko, húng. tengerszem 'pequeño lago alpino', lit. 'ojo de mar'. 
Pues bien, un problema etimológico es precisamente un problema histórico y, por lo tanto, el recurrir a la poligénesis, lejos de ser, como tan a menudo se piensa, un modo de resolverlo, es sólo un modo de plantearlo: no constituye explicación histórica, sino mera operación previa de separación de áreas; simplemente se divide un problema a primera vista único en varios problemas históricos independientes (o provisionalmente independientes), que luego se plantearán en particular para cada una de las áreas que se hayan deslindado.

7.2.4. Por ello, en el caso concreto de ojo de agua, la poligénesis de la imagen, aunque plenamente reconocida, no anula en realidad las dos hipótesis, muy razonables, que se han emitido para justificarla históricamente en lo que se refiere al área románica. Más aún: si no hubiera otras consideraciones, la hipótesis ibérica seguiría siendo una excelente hipótesis, y no por el simple hecho de que la imagen se encuentra en vascuence, sino porque el área que Rohlfs le señalaba coincide casi exactamente con el área normal de los llamados "iberismos". Menos convincente es la hipótesis árabe. Válida, sin duda, para el área hispánica a la que Castro se refería en España en su historia (esp., port., cat.), no puede, sin embargo, aplicarse a toda el área occidental de la metáfora. Sería todavía aceptable para el siciliano, pero mucho menos para el corso (pues no es enteramente exacto que Córcega haya estado bajo dominio árabe durante dos siglos: no se trató de dominio estable y efectivo, y el corso presenta muy escasos arabismos), y menos aún para el gascón y el provenzal (salvo que se entienda que a estas zonas la imagen se extendió desde el aragonés y el catalán, lo cual no parece muy probable).

De todos modos, también en este caso, la presencia de una imagen análoga en rumano viene a modificar esencialmente los datos mismos del problema y, según pienso, a exigir otra explicación.

7.2.5. El $D L R L C$ y el $D L R M$ dan, entre otros sentidos metafóricos de ochi 'ojo': 'extensión de agua, de forma redonda, en regiones pantanosas, rodeada de juncos' y 'lugar donde se junta y se estanca el agua'. Pero si esta última definición se refiere al significado que yo conozco de la Moldavia superior, donde transcurrió mi infancia y adolescencia, su formulación no me parece muy feliz, pues podría hacer pensar en un simple charco ocasional. En la Moldavia superior, en efecto, se llama ochi (pl. ochiuri) ${ }^{12}$ un 'pequeño venero,

$12 \mathrm{Y}$ no ochi de apă, que sería 'cualquier pequeña extensión de agua, de cualquier origen', desde un laguito hasta un charco de agua pluvial. Los dos diccionarios citados no distinguen entre ambos usos, y a ello se debe quizá lo impreciso de su definición, a pesar de que el $D L R L C$ da ejemplos precisamente del uso de ochi de apă, y no de ochi simplemente, como: ochiuri intunecoase de apă (Sadoveanu). En este caso, se trata de una metáfora común y que se advierte todavía como tal. Es un uso que parece reciente y podría no 
en terreno llano o pantanoso, que se estanca sin dar origen a un curso de agua permanente', mejor dicho, un 'hoyo natural, en terreno bajo, en el cual aflora el agua de manera intermitente, por lo general sobre una capa de cieno y tierra blanda, a veces bastante profunda', y, sólo en este sentido, también el resultante 'depósito de agua surgente, de poca extensión y de fondo cenagoso'. Yo diría que es la forma mínima, elemental, de lo que en el Uruguay y en la Argentina se llama un bañado (terreno pantanoso): en el ochi el agua no "mana" propiamente, no izvorăşte, como del izvor ('manantial'), sino que musteşte (emerge lentamente y con intermitencia). A veces, el och $i$ puede hallarse escondido entre la hierba, o bien, por bajar el nivel del agua subterránea, puede secarse superficialmente, y se presenta entonces como un lugar donde la superficie del terreno se hunde de repente, bajo el peso de un hombre, un animal o un vehículo, y revela el mismo depósito de cieno y agua cenagosa. Este mismo es el valor del término en la toponimia, en nombres como Ochiuri, Ochiu-alb, etc.: no se trata de 'charcos ocasionales', sino de 'manantiales sin desarrollo'13.

Ahora bien, este valor rumano concuerda de manera notable con algunos valores occidentales. Aunque los diccionarios no dan descripciones pormenorizadas de lo que se llama "ojo" en las lenguas románicas de Occidente, lo que proporcionan resulta, en varios casos, bastante revelador. Así, Corominas señala que, en catalán, más conocido aún que ull es el derivado ullal 'manantial, especialmente el de duración transitoria': y el ochi rumano es, justamente, transitorio, periódico. Mistral, como se ha visto, define el prov. uiau como 'petit gouffre': y los “ojos" rumanos son pequeños "gouffres", aunque cubiertos. No sé si también los campesinos moldavos los consideran como sin fondo, pero sé que los juzgan muy peligrosos y que cuentan de personas y animales que se hundieron en ciertos "ojos".

$\mathrm{Y}$ en español ¿qué significa ojo (de agua)? $\mathrm{El} D R A E$ lo define como 'manantial que surge en un llano'; y Corominas aclara que no significa rigurosamente 'manantial', sino "precisamente cada uno de los puntos de emergencia por donde el agua sale a la superficie". Pero en el Uruguay no significa esto, o por lo menos no significa sólo esto (y en la misma España, los célebres "ojos del Guadiana" no son "manantiales", "fuentes" del río Guadiana). En el campo uruguayo, según los varios informantes que he consultado, se llama ojo de agua (doy sus mismas definiciones): un "depósito de agua manantial de poca extensión"; una "capa subterránea de agua que emerge a la

tener nada que ver con el significado "técnico" y tradicional de ochi, que ya no es una "metáfora" sino un "nombre".

13 Lo de alb hace alusión a la capa de "sal" blanca que se forma sobre el ochi cuando éste se seca en la superficie, lo cual sucede en ciertos terrenos húmedos, salitrosos o calcáreos, llamados sărături ('salados'). 
superficie por un pequeño orificio, en un terreno bajo o llano, formando eventualmente un charco de escasas dimensiones"; una "«vertiente» que aflora en un llano formando un depósito de agua de poca extensión o un pequeño «bañado»": puede estar en el comienzo de una "cañada" (riachuelo), pero ello no es necesario, pues el ojo de agua, como tal, no es "fuente" de una corriente, sino un fenómeno autónomo. $\mathrm{Y}$, a pesar de que en una definición aparece el término vertiente ('manantial'), se me aclara que no se trata propiamente de un "manantial". Un informante especifica que del "manantial" el agua brota o mana, mientras que en el "ojo" el agua aflora, se filtra, inclusive sin un orificio definido de emergencia. Otro, que el "manantial" brota entre piedras, en la caída de una ladera, mientras que el "ojo de agua" surge en un llano, en tierra desnuda o "pastosa" (herbosa), y agrega que en el "ojo" el agua surge de manera "indefinida" e "irregular" (intermitente), mientras que del "manantial" brota en forma continua. Un tercero precisa que en el "ojo de agua" el agua "burbujea" con intermitencia y que el "ojo" puede ser periódico, mientras que del "manantial" -que es también más grande: es una "boca de agua", es permanente y se encuentra en un declive- el agua mana continuamente y con mayor fuerza. El mismo informante me señala que los "ojos de agua" son "traicioneros", pues el suelo que rodea al "ojo" puede ceder y en el hoyo que resulta pueden hundirse las ruedas de un vehículo; agrega, sin embargo, que no se trata de un hoyo muy hondo, pues un "ojo de agua" no llega a constituir un "tembladeral" (tremedal).

Es evidente que todo esto describe prácticamente el mismo fenómeno que se llama ochi en la Moldavia superior. La única diferencia que advierto es que el significado rumano insiste sobre el lugar (el ochi es un hecho de la tierra más bien que del agua), mientras que el significado uruguayo, sin dejar de aludir al lugar (se dice, por ejemplo, Vamos a tapar aquel ojo de agua), insiste más bien sobre el agua que aflora y sobre el depósito resultante.

7.2.6. En resumen, no se trata en rumano de una imagen más o menos genérica "ojo" = "fuente", sino de un significado bien preciso, "técnico", y que presenta sorprendentes coincidencias de detalle con los significados occidentales: a) el "ojo" surge en un llano (rum., cast., esp. del Uruguay); b) es un "petit gouffre" (rum., prov.); c) es periódico (rum., cat., esp. del Uruguay); d) en el "ojo" el agua no brota, sino que aflora de manera intermitente (rum., esp. del Uruguay); e) el "ojo" como tal no da origen a un curso de agua, no es una "fuente" (rum., esp. del Uruguay). Estas coincidencias, en primer lugar, son evidentemente lingüísticas, y no naturales, pues no se trata de características físicamente necesarias de cualquier manantial (y ni siquiera las coincidencias $b-d$ se refieren a caracteres necesarios de cualquier manantial en un llano). En segundo lugar, son tantas y 
tales que no pueden explicarse por un azar poligenético, y sí sólo por un origen común, como continuaciones de una tradición única. Pienso, pues, que también en este caso debemos suponer que los usos románicos proceden de un uso latino no documentado.

Y también en este caso, si hay arabismo (o iberismo) en los usos hispánicos, éste consistirá sólo en la extensión de un significado antiguo hasta coincidir con el significado de 'fuente' en general, pues, en efecto, para el español y el catalán se registran empleos que no parecen corresponder al valor que se acaba de delinear (unos ojos que nacen en un cerrillo; ull d'un rio) y que no serían posibles en rumano. Mejor dicho, en Hispania, un "ojo" románico se habrá encontrado y, en parte, confundido con un "ojo" árabe (o ibérico).

7.3.1. Con respecto a casa, A. Castro, España en su historia, p. 69, señala que "significó también 'habitación de una casa', arcaísmo que perdura en portugués", y que "en el siglo xvn todavía se decía en español «unas casas» por una casa, o «un par de casas» para designar una de dos pisos", y advierte que lo mismo ocurre en árabe: sugiere, por lo tanto, otro arabismo semántico. La sugerencia es aceptada por Lapesa en lo que se refiere a casa habitación de una casa', tanto en su reseña de la obra de Castro, $N R F H, 3$, p. 298, como en las ediciones $2^{\mathrm{a}}, 3^{\mathrm{a}}$ y $4^{\mathrm{a}}$ de su 'Historia de la lengua española (pp. 108, 107, 109). En cambio, Corominas, DCEC, s. v., señala para la Edad Media y el Siglo de Oro el uso común de designar con el plural casas "el edificio habitado por alguien" y agrega que hoy se conserva este uso en el habla rural argentina ${ }^{14}$, pero no habla de arabismo; recuerda, además, usos paralelos en el gallego del siglo xıI y en el mallorquín actual.

7.3.2. Ciertamente, por lo que toca al origen de estos usos, no parece necesario recurrir al árabe, ni siquiera para la sola Hispania, pues se encuentran en otras tradiciones más cercanas a los orígenes románicos. Así, cabría más bien sospechar un antiguo influjo griego sobre el llamado "latín vulgar". En griego, en efecto, tales usos eran muy comunes y frecuentes: desde los poemas homéricos, el plural de oikiov se empleaba para significar 'casa, palacio'; oî́os significaba 'casa' y 'habitación', y en plural designaba a menudo un solo edificio; ö̌ $\eta \mu a$ valía 'morada' y 'habitación', y en plural 'edificio, casa', etc. Por otra parte, en la misma tradición latina, los dos usos eran corrientes para el antiguo y clásico aedes -que, como es sabido, en singular significaba tanto 'casa' como 'habitación' y en plural significaba normalmente una 'casa' (cf. también aedicula 'cuartito' y aediculae 'casita')-, aunque no los hallo documentados para domus, villa, casa (pero me pregunto si casulas nostras, en Petronio, 46, 2, se referirá efectivamente a varias casas o más bien a una sola).

14 Es corriente también en el habla rural uruguaya. 
7.3.3. De todos modos, no se trata de hechos exclusivos de Hispania, dentro del dominio románico. En italiano antiguo el plural case significaba a menudo 'casa grande, palacio'. Y los dos usos hispánicos, tanto el plural para un solo edificio como casa 'habitación dentro de una casa', se encuentran exactamente idénticos en ruxuano. El $D L R L C$ registra o pereche [un par] de case y un rind [un "juego", lit. 'fila, serie'] de case 'casa grande, comúnmente de varias viviendas'; pero se dice también case, nişte case ('una casas') simplemente, sin o pereche o un rind, así como para un 'palacio' se emplea el plural curţi ("cortes'). El mismo diccionario da como "regional" la acepción de 'cameră, odaie' y señala las expresiones casa dinainte, casa mare, casa de oaspeţi. En la Moldavia superior, las casas rústicas de tamaño medio y normal, además de uno o dos ingresos (tindă, tinzi) y de eventuales dependencias, suelen abarcar las siguientes "casas": căsuţa (la 'casita'), al mismo tiempo cocina, comedor y sala de estar; casa de la vale (o de la deal, según la disposición del edificio), normalmente dormitorio, sobre todo de los hijos mozos; y casa cea mare, el cuarto de huéspedes, donde se guarda también el ajuar del ama de casa y de las hijas. Yo mismo, de chico, empleaba regularmente esas expresiones y no recuerdo haber advertido jamás la necesidad de distinguir entre casă 'edificio' y casă 'habitación en una casa'.

Universidad de Montevideo.

Eugenio Coseriu 